\title{
The Effect of Road Slope on Parameters of Disabled Vehicle Driven by PMDC Motor
}

\author{
Fatih Alpaslan Kazan * and Ramazan Akkaya
}

\begin{abstract}
In this study, the effect of road slope on the electrical and mechanical parameters of a disabled vehicle and regenerative braking was investigated on a 4 wheel disabled vehicle driven by a permanent magnet direct current (PMDC) motor. For this purpose, the test system, which was designed by the authors in order to test such vehicles in a laboratory environment, was developed in a way that allows the vehicle to be tested in external environments. This test system consists of a data acquisition card (DAC), related sensors, and an interface prepared in C\# program. Using the DAC, currents, voltages, speed, road slope, and temperatures were measured instantaneously during the test process and then transferred to the computer instantly. Using these data, the motor's speed, the motor's torque, the motor's shaft power, the yields of the motor and the driver, the vehicle's instantaneous speed, and the total covered distance were calculated during the experiment in realtime by the interface. At the same time, these data were graphed and saved. Tests were carried out on roads with a positive and negative slope. Finally, the data obtained from these tests were analyzed and the alterations in the electrical and mechanical parameters of the disabled vehicle depending on the road slope were clearly demonstrated by numerical data.
\end{abstract}

Index Terms - Data acquisition card, disabled vehicle, PMDC motor, regenerative braking, road slope, measurement.

\section{INTRODUCTION}

A VEHICLE THAT some or all of the mechanical energy required for its movement is provided from the electric motor(s) is called an electric vehicle. While determining the powers of the motors to be mounted on electric vehicles, the climbing angle of the vehicle and some forces affecting the vehicle are taken into account. These forces that oppose the

FATIH ALPASLAN KAZAN, is with Department of Aviation Electrical and Electronic of Selçuk University, Konya, Turkey, (e-mail: akazan@selcuk.edu.tr).

(iD) https://orcid.org/0000-0002-5461-0117

*Corresponding Author.

RAMAZAN AKKAYA, is with Department of Electrical and Electronic Engineering of Konya Technical University, Konya, Turkey, (e-mail: rakkaya@ktun.edu.tr).

iD https://orcid.org/0000-0002-6314-1500

Manuscript received May 9, 2021; accepted Jan 28, 2022.

DOI: $\underline{10.17694 / \text { bajece. } 935156}$ movement of the vehicle; aerodynamic (air) resistance, rolling resistance, acceleration resistance and gradient resistance.

The effect of aerodynamic resistance occurs when the vehicle's speed exceeds about $50 \mathrm{~km} / \mathrm{h}$ [1]. The rolling resistance consists of shape changes in roads and tires during rolling of the wheels and is expressed by a coefficient. The main reason for this resistance is that the tire is constantly deformed. It is also possible to reduce this with the appropriate wheel selection and tire pressure. Acceleration resistance occurs when the vehicle moves from the first speed to a second speed. This resistance is calculated by multiplying the vehicle's mass and the vehicle's instant acceleration. Therefore, this resistance value is zero for constant speed applications. Gradient resistance occurs due to the component of the weight parallel to the road during the movement of the vehicle on the inclined road. This resistance occurs on inclined roads [2].

Another point that is taken into consideration when determining the powers of the motors to be mounted on the vehicles is the vehicle's climbing ability. The maximum angle of inclination that a vehicle can climb at any constant speed is defined as the "ability to climb" of that vehicle.

Similar points need also to be taken into account when determining the power of the motor(s) to be installed in the battery-operated disabled vehicle, which are the biggest helpers of elderly and disabled people in carrying out their daily activities. In the study carried out by Akpunar [3], the power of a motor designed to carry $120 \mathrm{~kg}$ load on the batteryoperated disabled vehicle was calculated by considering the above-mentioned points. As a result of the calculations, it has been found that the motor to be mounted to the vehicle should produce $16.25 \mathrm{Nm}, 10 \mathrm{Nm}$ and $3.75 \mathrm{Nm}$ of torque on $+20^{\circ}, 0^{\circ}$ and $-20^{\circ}$ roads, respectively. This means that every $1^{\circ}$ change in road slope causes a change by $3.125 \%$ in torque. The literature was searched to find similar studies examining the change of the vehicle's parameters in relation to the road slope in the battery-operated disabled vehicles.

In the literature searches, it has been seen that very different studies have been carried out regarding the battery-operated disabled vehicles. Some of these are: controlling the disabled vehicle with head movement [4]-[9], voice [10]-[17], eye [18][24] and mouth movement [25]-[27]; using a fuzzy logic controller instead of conventional controller [28], [29]; examination of the vibration of the disabled vehicle under different road conditions [30]; measuring the mechanical and electrical impedances of the disabled vehicle with a sensor 
[31]; use of efficient motors to increase the vehicle's range [32]- [34]; detection of road slope [35]-[39]; examination of the effect of road gradient on the energy consumption of electric cars [40], [41]; investigation on the effect of different user weights on the energy consumption of the disabled vehicle driven by permanent magnet synchronous motor (PMSM) [42]; design of dc-dc buck converter for electric vehicles [43], [44]; maximizing of regenerative braking energy recovery of electric vehicles [45]. However, an experimental study that examines the change of vehicle parameters depending on the road slope and revealing this change clearly was not found in a disabled vehicle driven by permanent magnet direct current (PMDC) motor.

In the study previously conducted by the authors and presented in [42], the disabled vehicle was driven by PMSM $(650 \mathrm{~W})$, and the experiments were carried out on 2 constant slope routes with average slopes of $0.21^{\circ}$ and $1.44^{\circ}$, respectively. In the study where the effect of different user weights on the energy consumption of the vehicle was investigated, only the battery parameters were taken into consideration. The change of the parameters of the motor depending on the road slope or the regenerative braking effect was not investigated. In this new study, the changes of vehicle parameters, such as vehicle speed, battery current, battery voltage, the power drawn from the battery, motor's shaft power, and system efficiency, depending on the continuously changed road slope of the disabled vehicle driven by PMDC motor were demonstrated by experimental studies. In addition, it was also made an experimental study about regenerative braking becomes continuous at how many degrees.

\section{DESIGNED MEASURING SYSTEM AND COMPONENTS}

A system that enablers such disabled vehicles to be tested in the laboratory was previously introduced by the authors [46]. In this test system, battery's and motor's currents $\left(I_{b}\right.$ and $\left.I_{m}\right)$, motor's and battery's voltages $\left(V_{m}\right.$ and $\left.V_{b}\right)$, temperatures of motor and ambient $\left(T_{m}\right.$ and $\left.T_{a}\right)$, and vehicle speed $(v)$ were measured instantly and then sent to the computer.

These data sent to the computer were both monitored and recorded in real-time in the interface prepared in $\mathrm{C \#}$. In addition, using these data, the unmeasured quantities such as the speed of the motor $\left(N_{m}\right)$, the power drawn from the battery $\left(P_{b}\right)$, the motor's shaft power $\left(P_{s}\right)$, the torque produced by the motor $(T)$, and the motor and driver efficiencies $\left(E f f_{m}\right.$ and $\left.E f f_{d}\right)$ were also calculated instantly and plotted. Details of all these calculations were given in detail in [46]. The principle diagram of the new system with PMDC motor is given in Fig. 1. The rated voltage, the shaft power, and the speed of the PMDC motor in the disabled vehicle are $24 \mathrm{~V}, 750 \mathrm{~W}$, and $4000 \mathrm{rpm}$ respectively. The motor is controlled by a commercial driver with the code D51445 produced by PG Drives for use in disabled vehicles. The driver uses the PWM method.

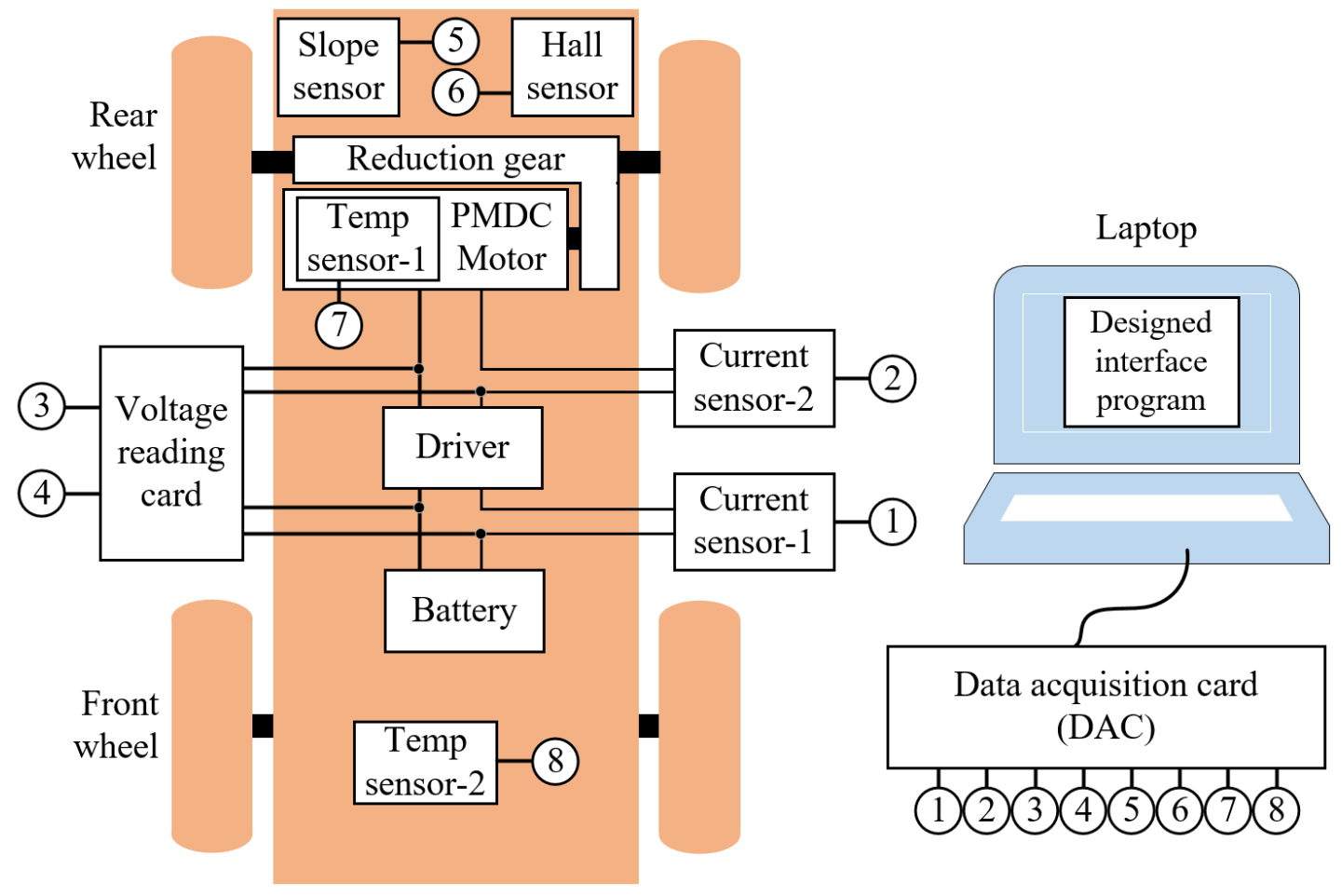

Fig. 1. The principle diagram of the designed test system.

\section{A. Voltage Measurement}

LV25P type voltage sensors manufactured by the LEM have been used to measure battery and motor terminal voltages. As is known, this sensor is a sensor that changes the output current according to the magnitude of the voltage at its input. The measurement is done by measuring the voltage that the 
current drops on a resistor connected to the output. The circuit diagram and final form of voltage reading card designed for measuring battery and motor terminal voltages are shown in Fig. 2.

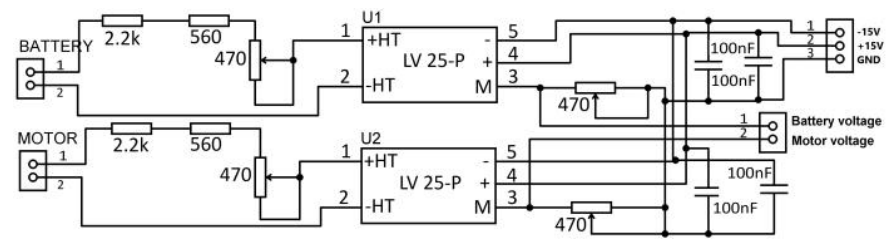

(a)

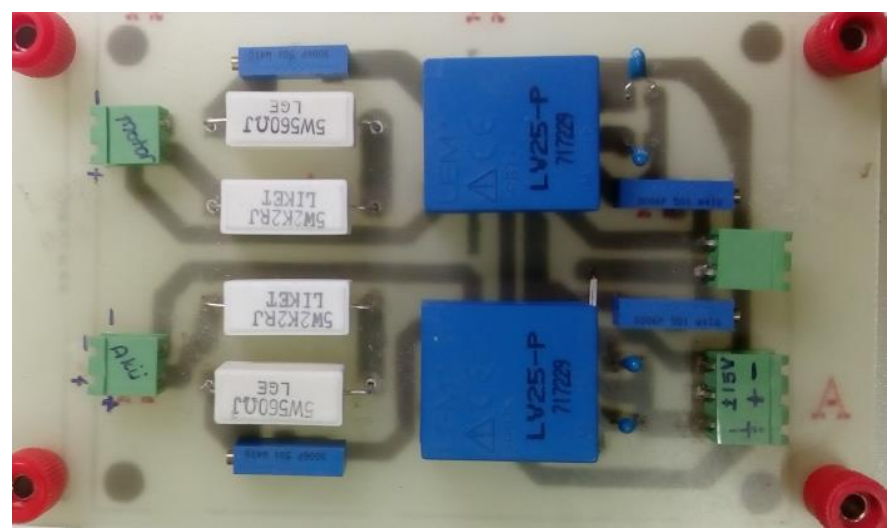

(b)

Fig. 2. The voltage reading card. (a) The open-circuit diagram. (b) Final form of the card.

\section{B. Current Measurement}

ACS712 series 30A current sensors (Fig. 3) have been used to measure battery and motor currents. It will also be possible to observe the regenerative braking effect as they allow bidirectional current measurement. As it is known, since these sensors give analogue output and can be supplied as a complete module, it is sufficient to connect their outputs directly to an analogue channel of a microcontroller.

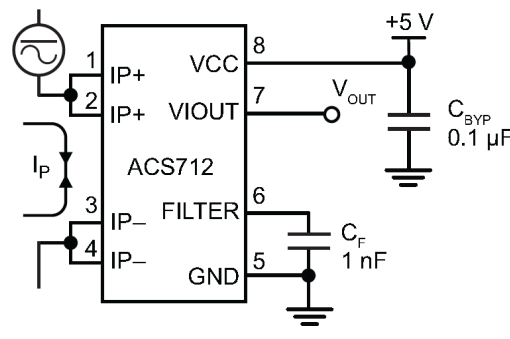

(a)

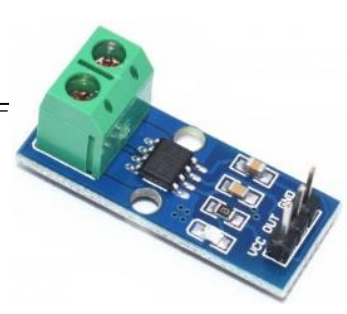

(b)
Fig. 3. ACS712-30A current sensor.

(a) The open-circuit diagram [47] (b) Final form of the card.

\section{Measurement of Road Slope}

SCA61T-FAHH1G coded incline sensor manufactured by the company named Murata has been used to measure the slope of the road on which the vehicle was tested. The measuring limit of this sensor is $\pm 30^{\circ}$. This sensor, which has a sensitivity of $0.0025^{\circ}$, can give analogue output. The sensor produces an oscillating output when exposed to accelerated motion or when used on a vibrating surface. The circuit diagram of the card designed for measuring the road slope is given in Fig. 4.

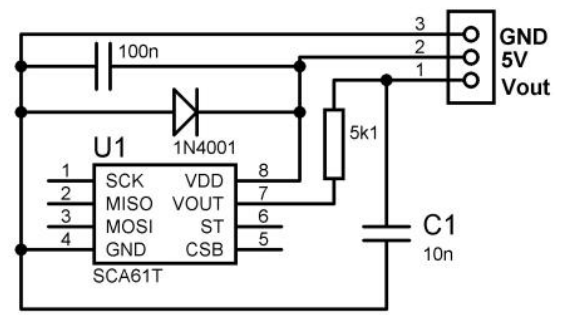

Fig. 4. The circuit diagram of the card designed for measuring the road slope

\section{Measurement of Vehicle Speed}

Vehicle speed plays a key role in calculating many parameters of the vehicle. Therefore, it is a quantity that must be measured. In the vehicle's outdoor tests, Hall sensor and magnets have been used to measure the speed. In this context, 24 equally spaced magnets have been placed on the rear right wheel of the vehicle to be tested. The A1101 series Hall sensor manufactured by the company named Allegro is positioned so that the distance between them is below $1 \mathrm{~cm}$ when it aligns with the magnets. The placement of the magnets and the Hall sensor are seen in Fig. 5.

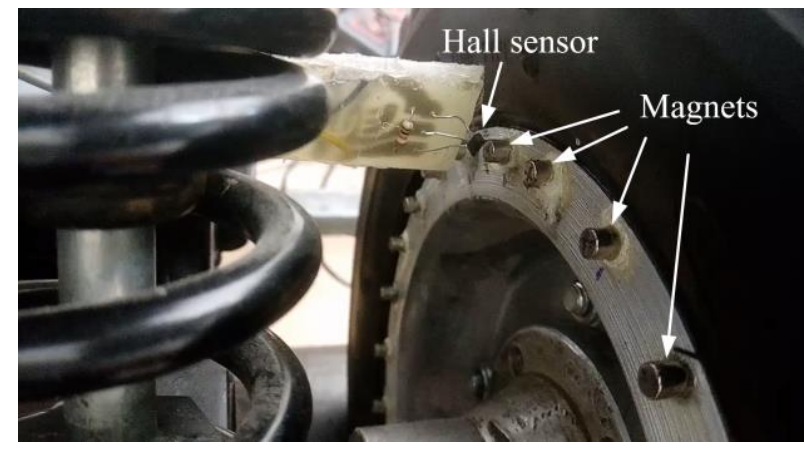

Fig. 5. Placement of the magnets and Hall sensor.

\section{E. Data Acquisition Card}

A data acquisition card (DAC) was designed to read the parameters and then to transfer them to the computer in realtime via USB. Low-priced PIC18F4550 was preferred as the microcontroller on the DAC and operated at $48 \mathrm{MHz}$ by using PLL (Phase Locked Loop) feature. The designed DAC is shown in Fig. 6.

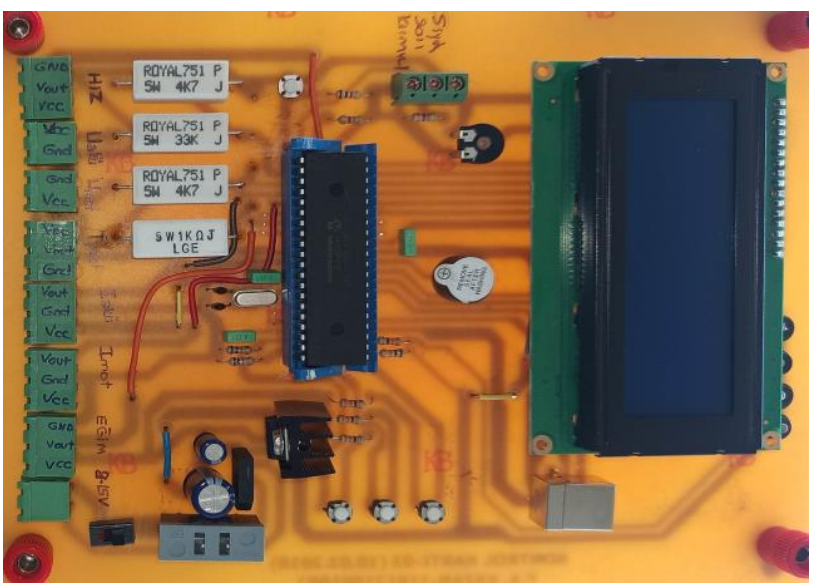

(a) 
BALKAN JOURNAL OF ELECTRICAL \& COMPUTER ENGINEERING， Vol. 10, No. 1, January 2022
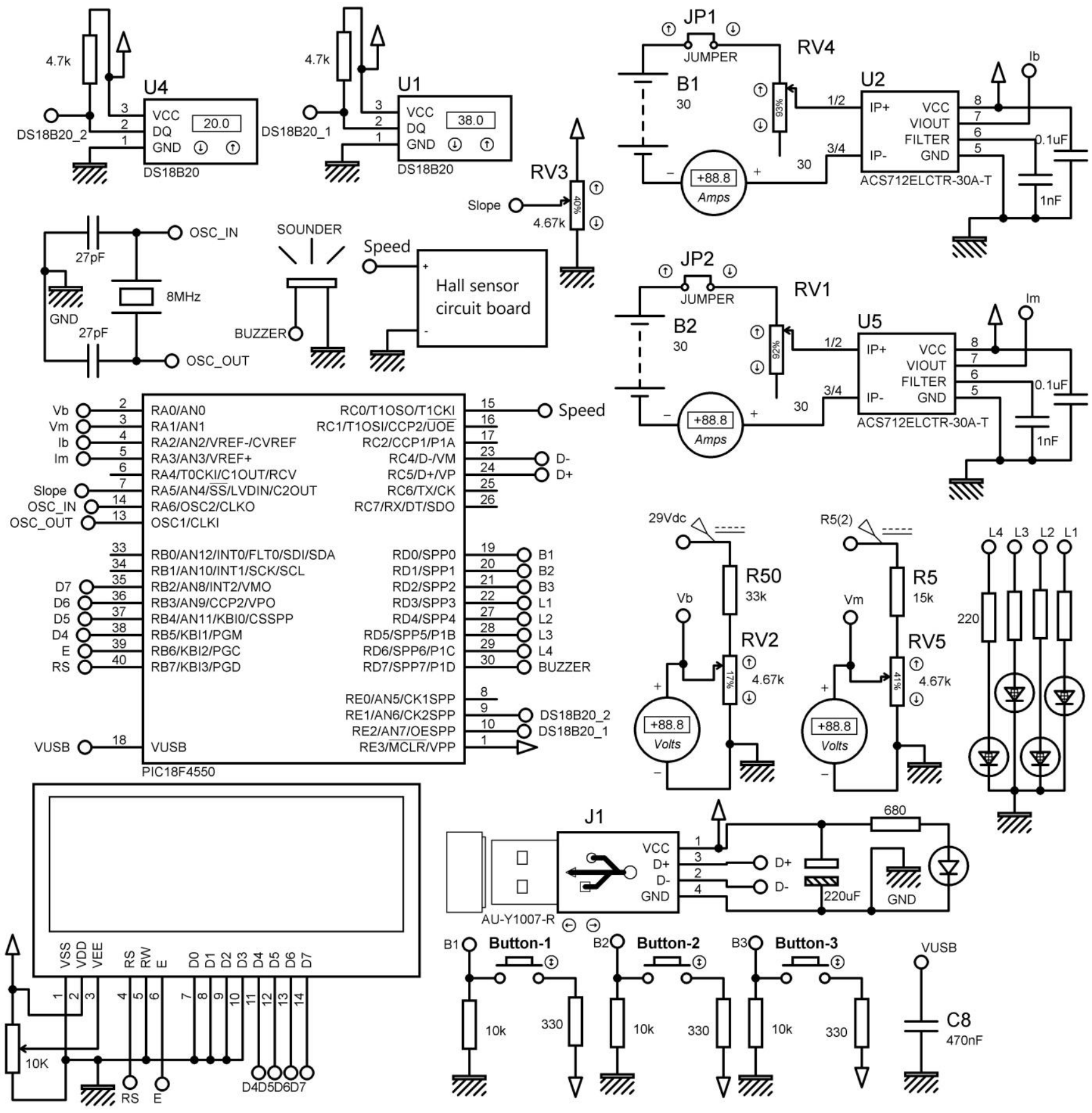

(b)

Fig. 6. The DAC. (a) Final form of the DAC. (b) The open-circuit diagram for simulation.

\section{F. Interface Program}

An interface program was designed using Visual $\mathrm{C} \#$ for viewing, processing, and storing the data sent by the DAC on the computer. The screenshot taken at the moment of the simulation of the DAC from the designed interface program is given in Fig. 7.

The interface program consists of 4 main sections. These are parameters section to be entered, measured and calculated values section, table section, and graphic section. How other quantities obtained using the measured data are calculated, is explained in detail in the study previously introduced by the authors in [46]. Therefore, it will not be explained here again. However, since the road slope was also measured in this study, minor revisions were made to the interface. The number of graphics drawn in the graphics section has also been increased from 10 to 13 .

Another innovation to the interface is the constant updating of the torque constant value entered into the interface, taking into account the test data from the PMDC motor manufacturer installed in the vehicle. The update process was done using an equation that was obtained by the curve fitting method and 
embedded in the interface program. Thus, the efficiency of the motor was obtained with an average error of $0.98 \%$ and without using any torque sensor. This situation is also seen in the efficiency graphs, which are presented in Fig. 8 and obtained when the motor is loaded at 7 different levels.

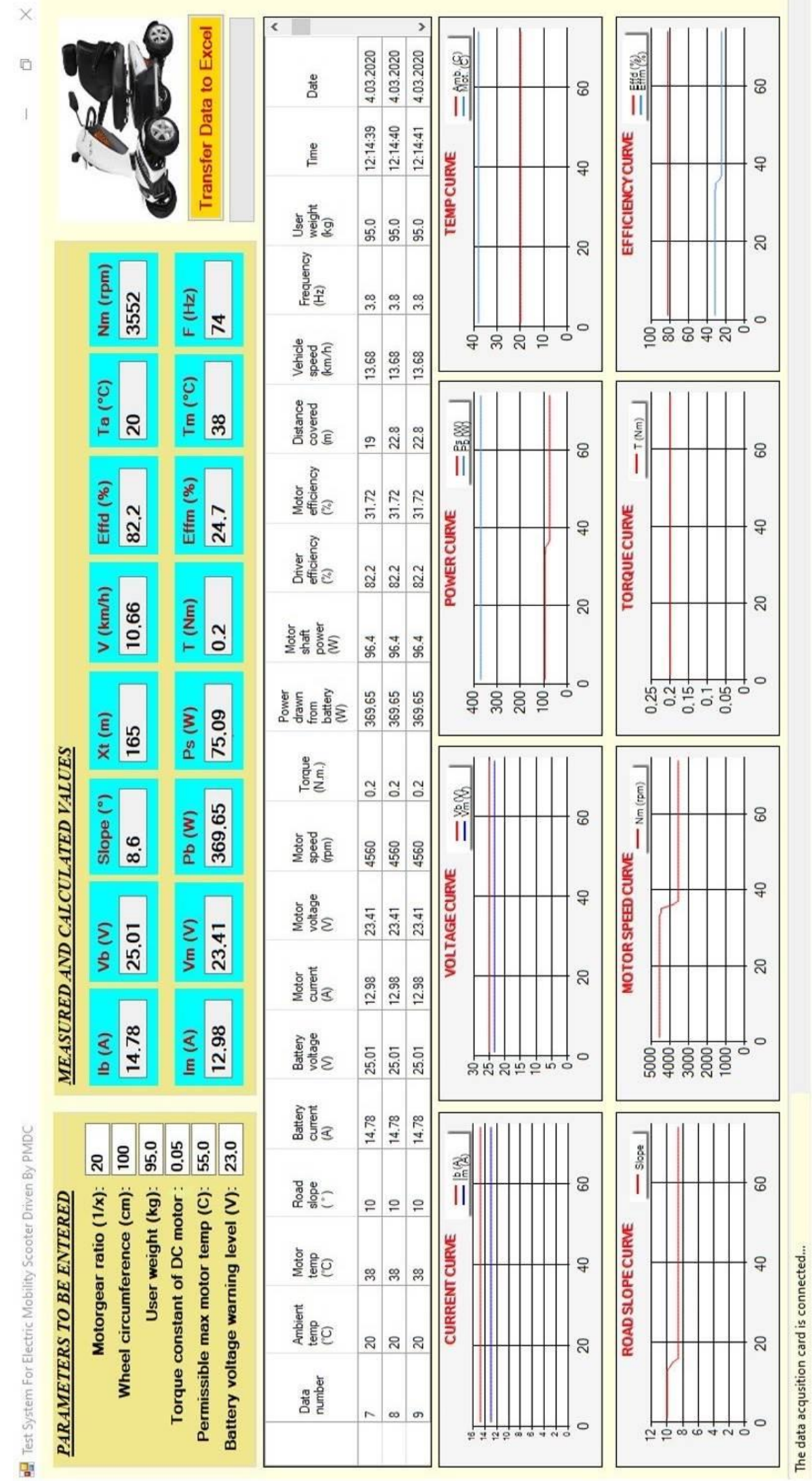

Fig. 7. Designed interface program. 


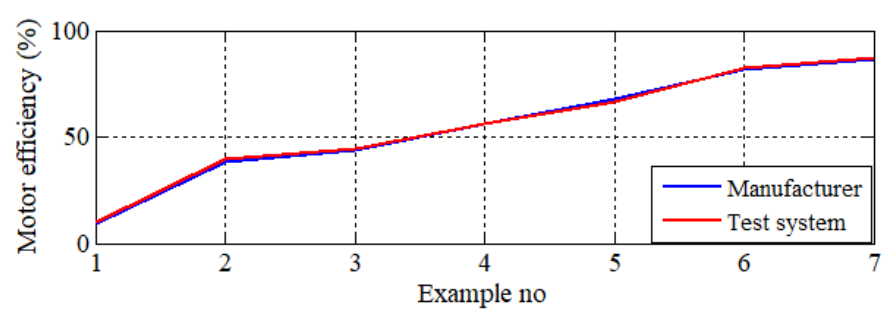

Fig. 8. Efficiency graphs of the PMDC motor in the disabled vehicle

\section{G. The Layout of System Components on the Disabled Vehicle}

The layouts of the system components on the vehicle is given in Fig. 9. The position of the designed DAC and voltage reading card can be seen in Fig. 9.a. In Fig. 9.b shows the rear of the disabled vehicle and the equipment located there.

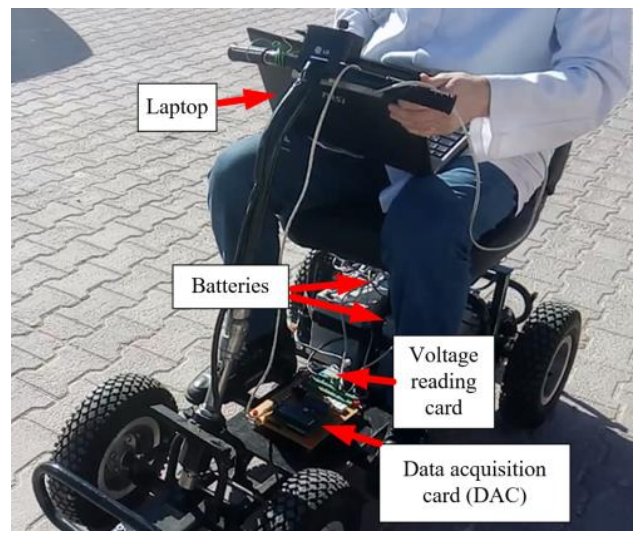

(a)

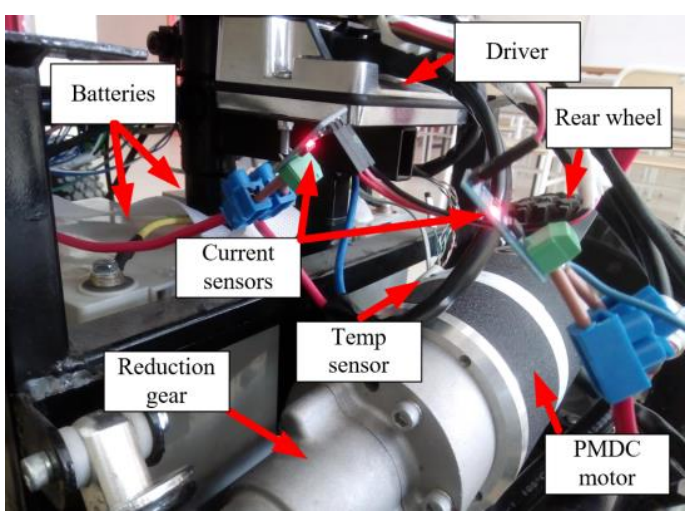

(b)

Fig. 9. The layouts of the system components on the vehicle. (a) The position of the designed DAC and voltage reading card. (b) The rear of the disabled vehicle and the equipment located there.

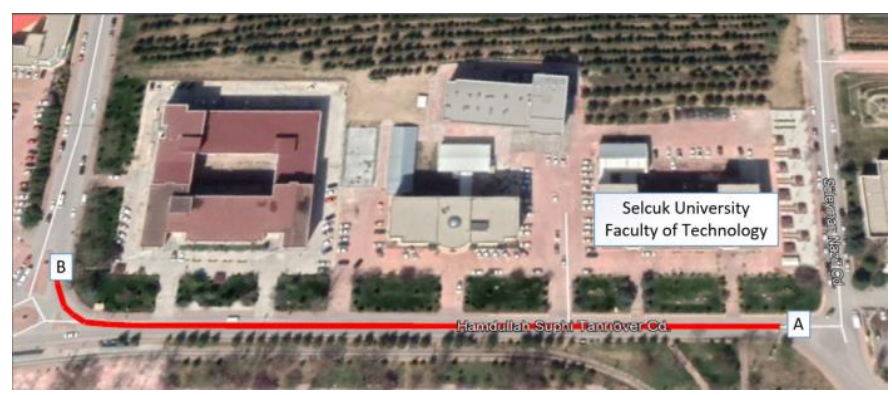

Fig. 10. Route-1.

\section{EXPERIMENTAL STUDIES}

In order to investigate the effect of the slope on the disabled vehicle driven with a PMDC motor, tests were carried out on different roads with different slopes at the Alaeddin Keykubat Campus of Selçuk University. First of all, tests which made on roads with positive slopes will be presented.

\section{A. Experimental Studies on Positive Slope Roads}

The first test was carried out on Route-1, shown in Fig. 10. During the test, the direction of the vehicle's movement is from point A to point B.

Changes in road slope, vehicle speed, current and power drawn from the battery, and battery terminal voltage throughout the test at Route-1 are given in Fig. 11.

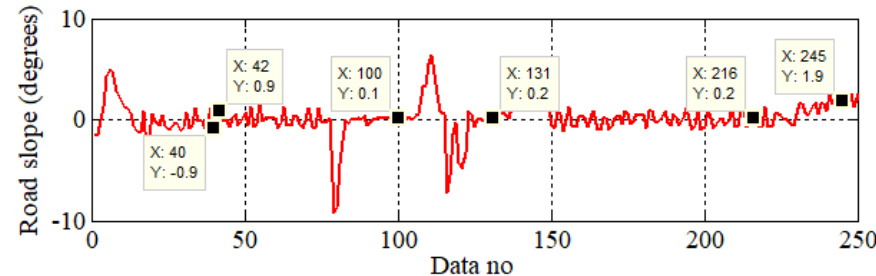

(a)

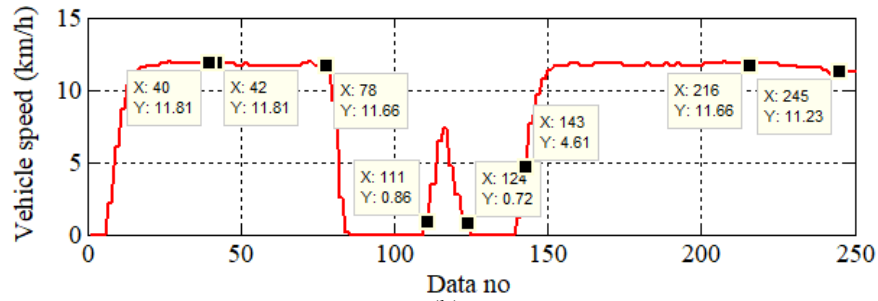

(b)

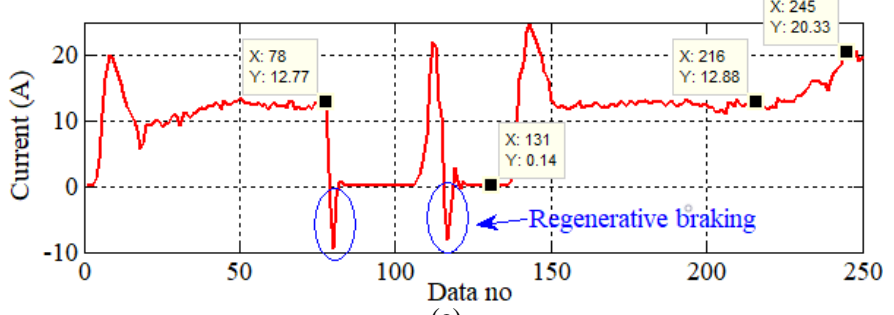

(c)

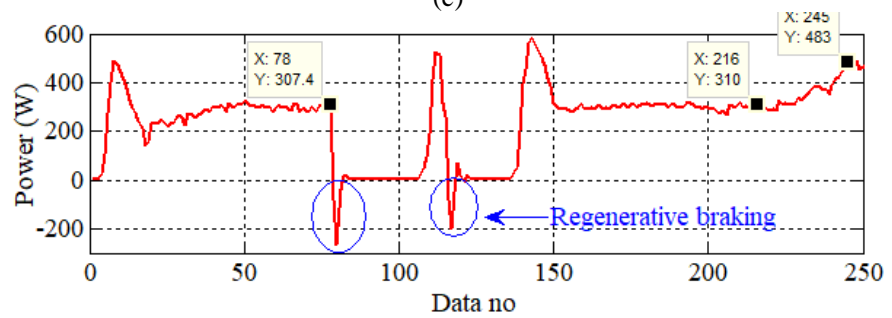

(d)

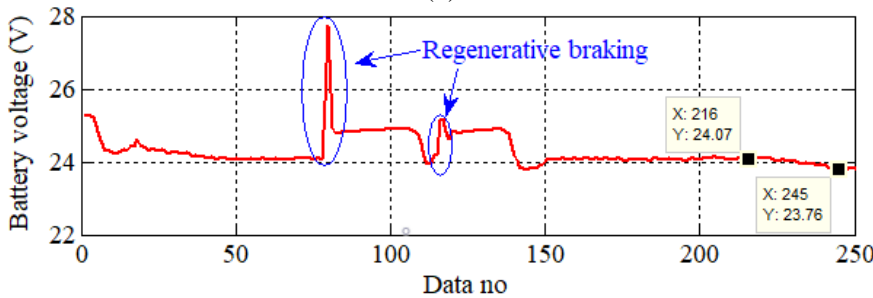

(e)

Fig. 11. Graphs related to the test on Route-1. (a) Road slope, (b) Vehicle speed, (c) Battery current, (d) Power drawn from the battery, (e) Battery terminal voltage. (Time difference between two consecutive data $0.4748 \mathrm{~s}$ ). 
The incline sensor produces oscillating results due to the accelerated and vibrating movement of the vehicle. When the slope and vehicle speed graphs in Fig. 11 are examined together: Although the tilt sensor produces a result well above and below normal during acceleration and deceleration, it produces an oscillating output that results only from the vibration of the vehicle but is relatively low compared to that of accelerated motion in areas where the speed is constant.

For example, when looking at the 40th and 42nd data in the speed graph, it is seen that the speed is constant $(11.81 \mathrm{~km} / \mathrm{h})$. When looking at the same numbered data in the slope graph, it is seen that the slope is $\pm 0.9^{\circ}$, so there is a difference of $1.8^{\circ}$ from peak to peak. This indicates that if the vehicle does not accelerate, there is only an error caused by the vehicle's vibration and the error value is approximately $\pm 0.9 \circ$ compared to the normal value. However, if the vibration of the sensor can be prevented, then a non-oscillating (absolute) result is obtained. This situation can be easily seen if the 100th and 131st data regions, where the vehicle is not moving, are examined. When the 100th and 131st data in the slope graph are taken into consideration, it is seen that the slops are $0.1^{\circ}$ and $0.2^{\circ}$, respectively.

In the slope graph in Fig. 11.a, it is seen that the road slope, which has an average of $0.2^{\circ}$, started to increase after 216 th data and reached an average of $1.9^{\circ}$ at the end of the experiment. The effect of this $1.7^{\circ}$ increase in slope on vehicle speed, current drawn from the battery, average of instantaneous power drawn from the battery $\left(P_{b}\right)$ and battery voltage is given in Table 1.

TABLE 1.

SUMMARY INFORMATION OF ROUTE-1.

\begin{tabular}{ccccc}
\hline$\alpha$ & $V_{b}$ & $I_{b}$ & $v$ & $P_{b}$ \\
$\left({ }^{\circ}\right)$ & $(\mathrm{V})$ & $(\mathrm{A})$ & $(\mathrm{km} / \mathrm{h})$ & $(\mathrm{W})$ \\
\hline 0.2 & 24.07 & 12.88 & 11.66 & 310 \\
1.9 & 23.76 & 20.33 & 11.23 & 483 \\
\hline
\end{tabular}

As can be find out from Table 1, the rising of road slope from $0.2^{\circ}$ to $1.9^{\circ}$ caused a decrease in battery voltage and vehicle speed by $1.29 \%$ and $3.69 \%$, respectively. However, the battery current and the average of instantaneous power drawn from the battery rose $57.8 \%$ and $55.8 \%$, respectively.

Testing on a road with an increasing slope will allow seeing the effect of the slope on parameters more clearly. For this purpose, the test was performed on Route-2, which shown in Fig. 12. Here, too, the direction of the vehicle's movement is from point $\mathrm{A}$ to point $\mathrm{B}$.

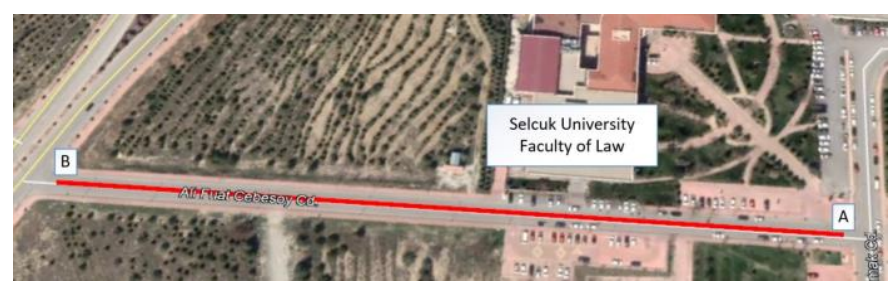

Fig. 12. Route-2

Changes in vehicle speed, road slope, battery current, battery voltage, the power drawn from the battery, and shaft power throughout the test at Route-1 are given in Fig. 13. In this test, only the behavior of the vehicle in the steady-state will be examined. The transient regimes of the vehicle, such as acceleration and deceleration, will not be taken into account. For this reason, the section up to 24th data, which is the acceleration zone of the vehicle, will not be taken into consideration in the graphics. Likewise, the region where the vehicle slows down and accelerates due to the speed bump placed on the road will be excluded from the analysis.

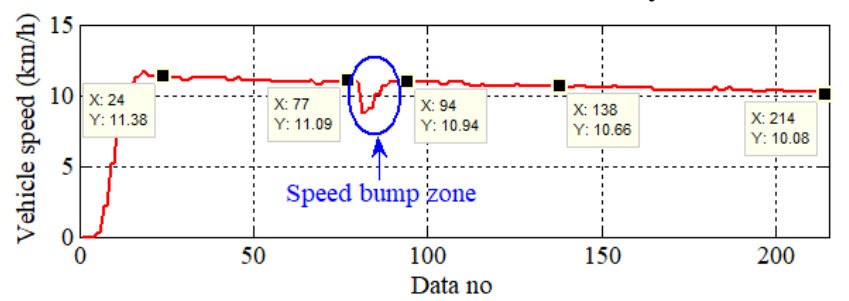

(a)

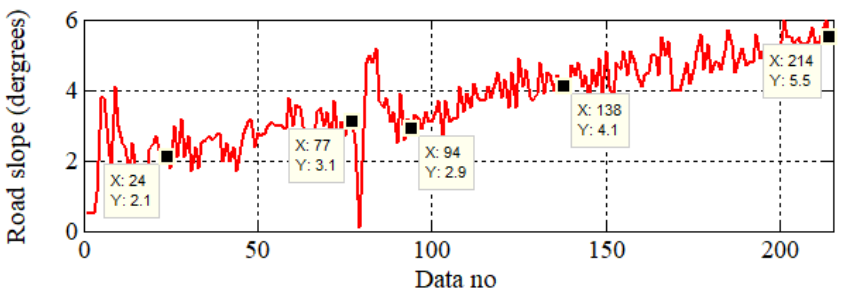

(b)

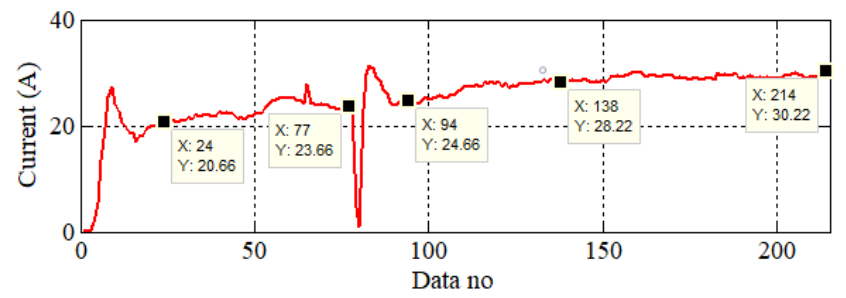

(c)

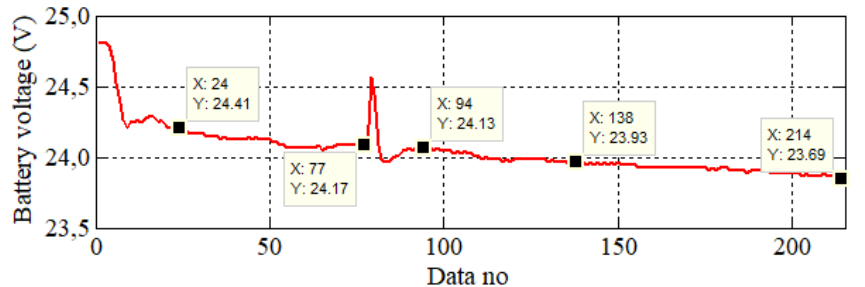

(d)

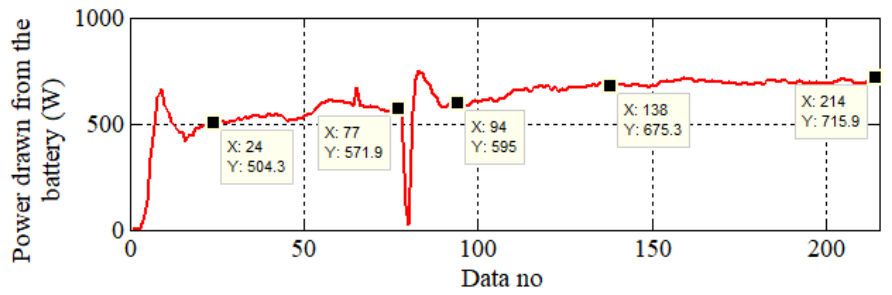

(e)

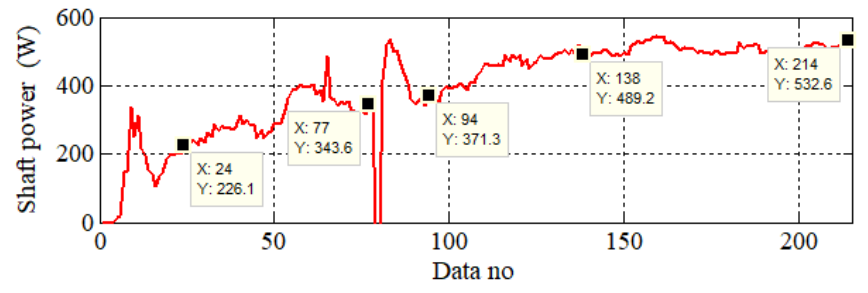

(f)

Fig. 13. Graphs related to the test on Route-2. (a) Vehicle speed, (b) Road slope, (c) Battery current, (d) Battery voltage, (e) Power drawn from the battery, (f) Shaft power (Time difference between two consecutive data $0.4711 \mathrm{~s})$. 
To facilitate understanding and interpretation of the data in the graphics, the points marked on the graphics and their related values have been collected in Table 2 . The system efficiency $\left(E f f_{s}\right)$, which is the ratio of the shaft power to the power drawn from the battery, has been also added to the last column of Table 2.

TABLE 2.

POINTS AND THEIR VALUES MARKED WITH THE HELP OF DATA CURSOR IN THE GRAPHS IN FIG. 13.

\begin{tabular}{cccccccc}
\hline $\begin{array}{c}\text { Data } \\
\text { no }\end{array}$ & $\begin{array}{c}\alpha \\
\left({ }^{\circ}\right)\end{array}$ & $\begin{array}{c}I_{b} \\
(\mathrm{~A})\end{array}$ & $\begin{array}{c}V_{b} \\
(\mathrm{~V})\end{array}$ & $\begin{array}{c}v \\
(\mathrm{~km} / \mathrm{h})\end{array}$ & $\begin{array}{c}P_{b} \\
(\mathrm{~W})\end{array}$ & $\begin{array}{c}P_{s} \\
(\mathrm{~W})\end{array}$ & $\begin{array}{c}E f f_{s} \\
(\%)\end{array}$ \\
\hline 27 & 2.1 & 20.66 & 24.41 & 11.38 & 504.3 & 226.1 & 44.83 \\
77 & 3.1 & 23.66 & 24.17 & 11.09 & 571.9 & 343.6 & 60.08 \\
94 & 2.9 & 24.66 & 24.13 & 10.94 & 595.0 & 371.3 & 62.40 \\
138 & 4.1 & 28.22 & 23.93 & 10.66 & 675.3 & 489.2 & 72.44 \\
214 & 5.5 & 30.22 & 23.69 & 10.08 & 715.9 & 532.6 & 74.40 \\
\hline
\end{tabular}

As may remember, in the previous test, the battery current, which was $12.88 \mathrm{~A}$ at a road slope of $0.2^{\circ}$, increased to 20.33 A when the road slope was rose to $1.9^{\circ}$. In this test, too, the measurement of the battery current as $20.66 \mathrm{~A}$ at a road slope of $2.1^{\circ}$ indicates that the system operates stably.

\section{B. Experimental Studies on Negative Slope Roads}

In order to research the effect of negative slope on the vehicle parameters, Route-3 given in Fig. 14 was chosen. In Route-3, which has a negative slope along approximately 900 $\mathrm{m}$, the direction of the vehicle's movement is from point $\mathrm{A}$ to point B.

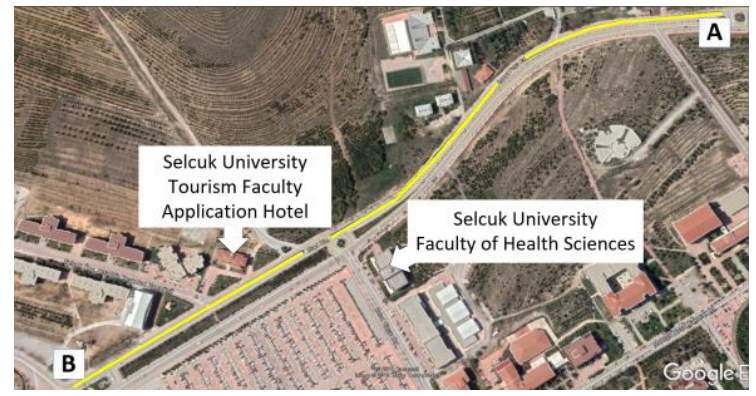

Fig. 14. Route-3

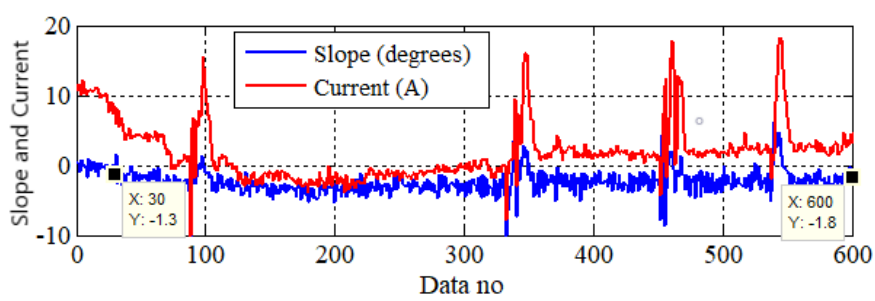

(a)

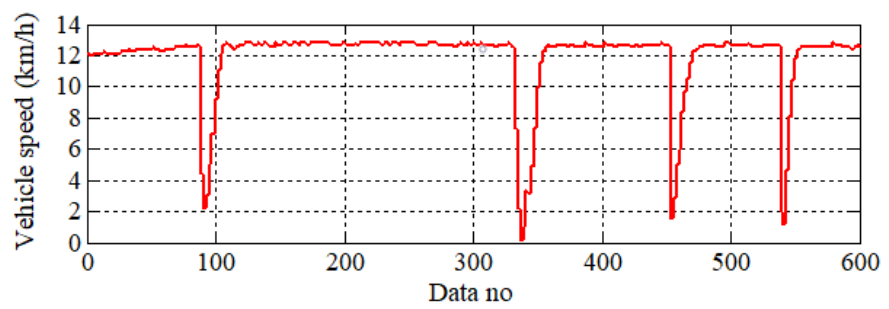

(b)

Fig. 15. Graphics of the test on the road with a negative slope (a) Slope and current graphic, (b) Vehicle speed graphic (Time difference between two consecutive data $0.4859 \mathrm{~s}$ ).
In the test carried out in Route-3, changes in road slope, current drawn from the battery, and vehicle speed throughout the test are given in Fig. 15. The current and slope are given in the same graph (in Fig. 15.a) in order to see the change of current depending on the road slope more clearly.

When the slope graph is examined, it is seen that the slope starts to get negative value continuously starting from the 30th data. The negative slope continues regularly up to 600th data, except for the transient regime resulting from lowering and reraising the vehicle speed due to speed bump on the road. The decrease and increase in vehicle speed which is the source of this transient regime will be seen when the speed graph in Fig. $15 . \mathrm{b}$ is examined.

Depending on the value of the slope, in order to see more clearly the current value that regenerative braking starts, the slope-current graphic has been enlarged between 120th-300th data and 350th-600th data and given in Fig. 16.

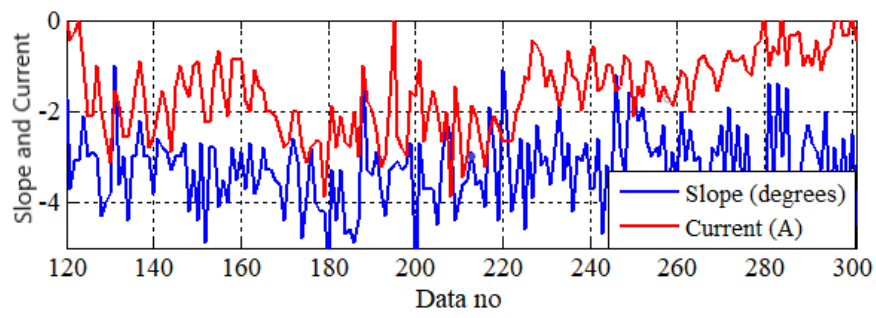

(a)

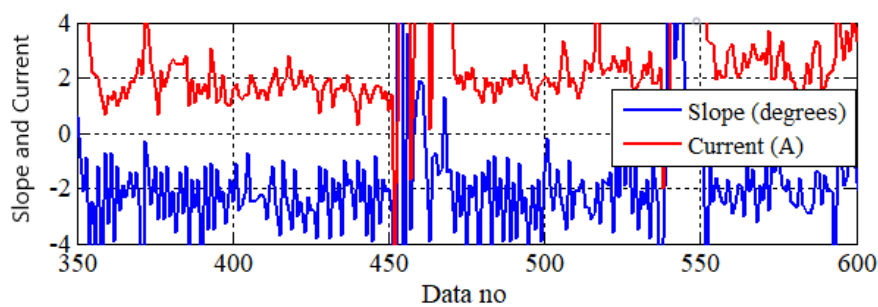

(b)

Fig. 16. Zooming of certain regions in the slope-current graphic of regenerative braking (a) 120th-300th data range, (b) 350th-600th data range (Time difference between two consecutive data $0.4859 \mathrm{~s}$ ).

In Fig. 16.a, it can be seen that in regions where the average slope is less than $-3^{\circ}$, the battery current has a significantly negative value, that is, the battery is charged. In Fig. 16.b, it is seen that the battery current has a positive value in the regions where the slope is $-2^{\circ}$ and larger, that is, the battery is discharged. However, in this region, the current drawn from the battery is quite small compared to the flat road and it varies in the range of $1.5 \mathrm{~A}$ and $2.5 \mathrm{~A}$ on average. This value is the current drawn to disable the vehicle's electromagnetic brake system.

The main component affected by the negative road slope is undoubtedly the battery. Therefore, examining the variation of the power drawn from the battery and the battery voltage throughout the test will enable us to see the effect of the negative slope from a different angle. The graphics related to this are given in Fig. 17.

When the graphic of power drawn from the battery in Fig. 17.a is examined, it is seen that the power flow is continuously from the motor to the battery in the 121th-299th data range. That is, the battery is continuously be charging due to the 
negative road slope. After 299th data, it is noteworthy that, except for the transient regimes, the slope is always negative, but power is drawn from the battery.

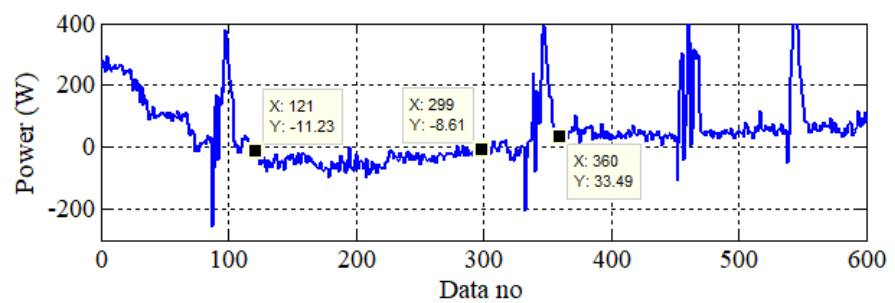

(a)

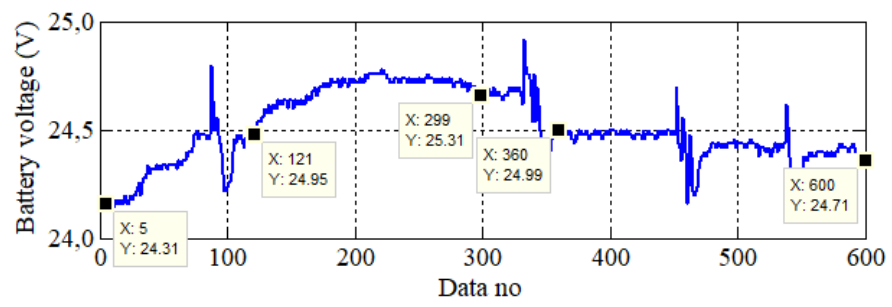

(b)

Fig. 17. Graphics of regenerative braking test (a) Power drawn from the battery, (b) Battery terminal voltage (Time difference between two consecutive data $0.4859 \mathrm{~s}$ ).

When the battery voltage graphic in Fig. 17.b is examined, it is seen that the battery terminal voltage rises by $0.36 \mathrm{~V}$ (from $24.95 \mathrm{~V}$ to $25.31 \mathrm{~V}$ ) among 121th-299th data where the battery is being charged continuously. When it is examined after the 360th data (the section after the speed bump), it is observed that the battery terminal voltage decreases gradually due to the gradual increase of the power drawn from the battery. When the entire test is taken into consideration, it is seen that the battery voltage, which was initially $24.31 \mathrm{~V}$, increased to $24.71 \mathrm{~V}$ at the end of the test.

\section{DiscusSiON OF THE OBTAINED DATA}

In the tests carried out, the following results were obtained when the road slope increased from $0.2^{\circ}$ to $1.9^{\circ}$ :

- The power drawn from the battery increased by $55.8 \%$.

- Battery terminal voltage decreased by $1.29 \%$.

- The current drawn from the battery increased by $57.8 \%$.

- Vehicle speed decreased by $3.69 \%$.

In order to see the effect of road slope on these parameters more clearly, it was made a test with the same user but on another route with more slope. When the slope of the road increased by $3.4^{\circ}$ (from $2.1^{\circ}$ to $5.5^{\circ}$ ), the following results were obtained:

- The current drawn from the battery increased by $46.27 \%$. When the battery current in the $0.2^{\circ}$ road slope is taken as reference, the $5.3^{\circ}$ increase in the slope led to an increase of $134.63 \%$ in the current. Therefore, every $1^{\circ}$ increase in road slope has caused an average increase of $25.40 \%$ in the battery current.

- Battery voltage decreased by $2.95 \%$.

- Even when the vehicle reached a slope of $5.5^{\circ}$, PMDC motor used only $71.01 \%$ of its rated power $(750 \mathrm{~W})$.

- System efficiency increased from $44.83 \%$ to $74.40 \%$.

- Vehicle speed decreased by $11.42 \%$.

- Shaft power increased by $135.56 \%$.
When the change in the shaft power and in the speed are evaluated together, it is seen that the increase in the road slope by $3.7^{\circ}$ caused an increase in torque by $65.94 \%$. Therefore, $1^{\circ}$ increase in the road slope causes to produce $19.39 \%$ more torque of the motor. However, in the study conducted using basic formulas and given in [2], this value appears as $3.125 \%$.

When the shaft power column in Table 2 is examined, it is seen that $532.6 \mathrm{~W}$ shaft power is sufficient even on an extreme road slope of $5.5^{\circ}$. If the disabled vehicle used in the experiment is used on roads where such extreme slopes will not exist, the motor shaft power it needs will remain below $300 \mathrm{~W}$. Because even on a road slope of $2.1^{\circ}$, the motor shaft power of $226.1 \mathrm{~W}$ was sufficient for the movement of the vehicle (Table 2). Therefore, using a motor with a shaft power of $750 \mathrm{~W}$ only increases the losses. The increase in losses means unnecessary energy withdrawal from the battery. This directly means that the battery charge is consumed unnecessarily and the battery is discharged in a shorter range.

In the tests performed, it was observed that the battery current had a clearly negative value if the average slope was less than $-3^{\circ}$. In other words, regenerative braking occurred and the battery charged. If the road slope is $-2^{\circ}$ and bigger, it has observed that the battery current was positive, that is, the battery discharged. However, if the road slope is in the range of $0^{\circ}$ to $-2^{\circ}$, the current value drawn from the battery was observed to be small enough to disable the vehicle's electromagnetic brake system and its value ranged from $1.5 \mathrm{~A}$ to $2.5 \mathrm{~A}$.

\section{CONCLUSION}

In this study, the effects of road slope on disabled vehicle speed, battery current, battery voltage, the power drawn from the battery, the motor shaft power, and the system efficiency were examined in the street tests of the disabled vehicle with PMDC motor used by $95 \mathrm{~kg}$ user. When the numerical data obtained from the experiments were evaluated, the following three main conclusions were reached.

- When determining the powers of the motors to be installed on the disabled vehicle, it should be taken into consideration whether the disabled vehicle will be used on inclined roads and unnecessarily high power motors should be avoided. Therefore, by choosing only a motor with suitable power, it will be possible for the disabled vehicle to travel longer with the same charge. In addition, because the frequency of charging the batteries will decrease, the life of the battery will increase.

- According to the formula-based study in [2], $1^{\circ}$ increase in road slope requires to produce $3.15 \%$ more torque of the motor. However, in this experimental study, it was revealed that this value was $19.39 \%$.

- It has been observed that regenerative braking in disabled vehicles does not contribute much to the charge of the battery, except that it reduces the vehicle speed. Because the battery does not start to charge unless the road slope falls below a certain value. In the test carried out on the road (Route-3) with a continuous negative slope for approximately $940 \mathrm{~m}$, it was observed that the battery was charged only when the road slope was less than $-3^{\circ}$. On road slopes of $-2^{\circ}$ and greater, the battery continues to discharge. 


\section{ACKNOWLEDGMENT}

This study is part of the project supported by Selçuk University Scientific Research Projects Coordination Office. The project number is 17101008 .

\section{REFERENCES}

[1] K. B. Kelly and H. J. Holcombe, "Aerodynamics for body engineers," SAE Transactions, pp. 570-578, 1964.

[2] A. N. Gent, and J. D. Walter, "Pneumatic Tire", Mechanical Engineering Faculty Research. 854, the University of Akron, Ohio, USA, 2006.

[3] A. Akpunar, "Ergonomik Bir Elektrikli Tekerlekli Sandalye İçin Dişlisiz Ve Direkt Sürmeli Bir Elektrik Motor Tasarımı," Yüksek Lisans, Fen Bilimleri Enstitüsü, Muğla Üniversitesi, Muğla, 2007.

[4] G. Marins, D. Carvalho, A. Marcato, and I. Junior, "Development of a control system for electric wheelchairs based on head movements," in Intelligent Systems Conference (IntelliSys), 2017, IEEE, pp. 996-1001.

[5] S. Nasif and M. A. G. Khan, "Wireless head gesture controlled wheel chair for disable persons," in Humanitarian Technology Conference (R10-HTC), 2017 IEEE Region 10, 2017: IEEE, pp. 156-161.

[6] S. Yokota, H. Hashimoto, Y. Ohyama, J.-H. She, D. Chugo, H. Kobayashi, and P. Blazevic, "Study on human body motion interface," in ICCAS-SICE, 2009, pp. 3264-3267.

[7] D. Kupetz, S. Wentzell, and B. Busha, "Head motion controlled power wheelchair," in Proceedings of the 2010 IEEE 36th Annual Northeast Bioengineering Conference (NEBEC), 2010, pp. 1-2.

[8] J. M. Ford and S. J. Sheredos, "Ultrasonic head controller for powered wheelchairs," Journal of Rehabilitation Research and Development, vol. 32, pp. 280-284, 1995.

[9] F. A. Kondori, S. Yousefi, L. Liu, and H. Li, "Head operated electric wheelchair," in 2014 Southwest Symposium on Image Analysis and Interpretation, 2014: IEEE, pp. 53-56.

[10] P. Ghule, M. Bhalerao, R. Chile, and V. G. Asutkar, "Wheelchair control using speech recognition," in 9th International Conference on Contemporary Computing (IC3), 2016: IEEE, pp. 1-6.

[11] R. Chauhan, Y. Jain, H. Agarwal, and A. Patil, "Study of implementation of Voice Controlled Wheelchair," in 3rd International Advanced Computing and Communication Systems (ICACCS), 2016, pp. 1-4.

[12] D. Wang and H. Yu, "Development of the control system of a voiceoperated wheelchair with multi-posture characteristics," in 2nd AsiaPacific Conference on Intelligent Robot Systems, 2017, pp. 151-155.

[13] A. Škraba, R. Stojanović, A. Zupan, A. Koložvari, and D. Kofjač, "Speech-controlled cloud-based wheelchair platform for disabled persons," Microprocessors and Microsystems, vol. 39, pp. 819-828, 2015.

[14] M. F. Ruzaij, S. Neubert, N. Stoll, and K. Thurow, "Design and testing of low cost three-modes of operation voice controller for wheelchairs and rehabilitation robotics," in IEEE 9th International Symposium on Intelligent Signal Processing (WISP) Proceedings, 2015, pp. 1-6.

[15] M. F. Ruzaij and S. Poonguzhali, "Design and implementation of low cost intelligent wheelchair," in International Conference on Recent Trends in Information Technology, 2012, pp. 468-471.

[16] M. A. Alim, S. Setumin, A. D. Rosli, and A. I. C. Ani, "Development of a Voice-controlled Intelligent Wheelchair System using Raspberry Pi," in 2021 IEEE 11th IEEE Symposium on Computer Applications \& Industrial Electronics (ISCAIE), 2021, pp. 274-278.

[17] M. S. Amin, S. T. H. Rizvi, S. Malik, Z. B. Faheem, and A. Liaqat, "Smart Wheelchair-An Implementation of Voice and Android Controlled System," in 2021 International Conference on Digital Futures and Transformative Technologies (ICoDT2), 2021, pp. 1-6.

[18] P. S. Gajwani and S. A. Chhabria, "Eye motion tracking for wheelchair control," International Journal of Information Technology, vol. 2, pp. 185-187, 2010.

[19] M. Jain, S. Puri, and S. Unishree, "Eyeball motion controlled wheelchair using IR sensors," International Journal of Computer and Information Engineering, vol. 9, pp. 906-909, 2015.

[20] J. Sharma, M. Anbarasu, C. Chakraborty, and M. Shanmugasundaram, "Iris movement based wheel chair control using raspberry $\mathrm{Pi}-\mathrm{A}$ state of art," in Power and Advanced Computing Technologies (i-PACT), 2017, pp. 1-5.
[21] K. Arai and R. Mardiyanto, "Eyes based electric wheel chair control system," International Journal of Advanced Computer Science and Applications (IJACSA), vol. 2, 2011.

[22] Q. X. Nguyen and S. Jo, "Electric wheelchair control using head pose free eye-gaze tracker," IET Electronics Letters, vol. 48, pp. 750-752, 2012.

[23] M. Subramanian, N. Songur, D. Adjei, P. Orlov, and A. A. Faisal, "A. Eye Drive: Gaze-based semi-autonomous wheelchair interface," in 41st Annual International Conference of the IEEE Engineering in Medicine and Biology Society (EMBC), 2019, pp. 5967-5970.

[24] M. Subramanian, S. Park, P. Orlov, A. Shafti, and A. A. Faisal, "Gazecontingent decoding of human navigation intention on an autonomous wheelchair platform," in 2021 10th International IEEE/EMBS Conference on Neural Engineering (NER), 2021, pp. 335-338.

[25] J. Ju, Y. Shin, and E. Kim, "Intelligent wheelchair using head tilt and mouth shape," IET Electronics letters, vol. 45, pp. 873-875, 2009.

[26] E. Ko, J. S. Ju, E. Y. Kim, and N. S. Goo, "An intelligent wheelchair to enable mobility of severely disabled and elder people," in Digest of Technical Papers International Conference on Consumer Electronics, 2009, pp. 1-2

[27] J. S. Ju, Y. H. Shin, E. Y. Kim, and S. H. Park, "Intelligent wheelchair using face and mouth shape recognition," in Digest of Technical PapersInternational Conference on Consumer Electronics, 2008, pp. 1-2.

[28] V. Sankardoss and P. Geethanjali, "Design and low-cost implementation of an electric wheelchair control," IETE Journal of Research, pp. 1-10, 2019.

[29] N. Tanohata, H. Murakami, and H. Seki, "Battery friendly driving control of electric power-assisted wheelchair based on fuzzy algorithm," in Proceedings of SICE Annual Conference, 2010, pp. 1595-1598.

[30] T. Wang, J. i. Kaneko, and K. Kojima, "Study on relevance between electric wheelchair riding comfort and user exposure to whole-body vibration," in IEEE 6th Global Conference on Consumer Electronics, 2017, pp. 1-2.

[31] H. M. Hondori, P. Q. Trung, and L. Shih-Fu, "Simultaneous sensing and actuating for path condition monitoring of a power wheel chair," in First RSI/ISM International Conference on Robotics and Mechatronics, 2013, pp. 343-346.

[32] Y.-K. Kim, Y.-H. Cho, N.-C. Park, S.-H. Kim, and H.-S. Mok, "InWheel motor drive system using 2-phase PMSM," in 6th International Power Electronics and Motion Control Conference, 2009, pp. 18751879.

[33] F. A. Kazan and R. Akkaya, "Use of PMSM in Electric Mobility Scooter Propulsion," in International Conference on Engineering Technologies (ICENTE'19), Konya, Turkey, 2019.

[34] İ. Tarımer, A. Akpunar, and R. Gürbüz, "Design of a direct sliding gearless electrical motor for an ergonomic electrical wheelchair," Elektronika IR Elektrotechnika, vol. 83, pp. 75-80, 2008.

[35] B. Li, J. Zhang, H. Du, and W. Li, "Two-layer structure based adaptive estimation for vehicle mass and road slope under longitudinal motion," Measurement, vol. 95, pp. 439-455, 2017.

[36] K. Jo, M. Lee, and M. Sunwoo, "Road slope aided vehicle position estimation system based on sensor fusion of GPS and automotive onboard sensors," IEEE Transactions on Intelligent Transportation Systems, vol. 17, pp. 250-263, 2015.

[37] K. Jo, J. Kim, and M. Sunwoo, "Real-time road-slope estimation based on integration of onboard sensors with GPS using an IMMPDA filter," IEEE Transactions on Intelligent Transportation Systems, vol. 14, pp. 1718-1732, 2013.

[38] J.-H. Jang, S.-H. Bae, M.-W. Park, and J.-H. Kim, "Research of velocity control on the slope road for Unmanned Ground Vehicle," in International Conference on Control, Automation and Systems, 2010, pp. 1085-1088.

[39] M. F. Ruzaij, S. Neubert, N. Stoll, and K. Thurow, "A speed compensation algorithm for a head tilts controller used for wheelchairs and rehabilitation applications," in IEEE 15th International Symposium on Applied Machine Intelligence and Informatics (SAMI), 2017, pp. 497-502.

[40] S. Yang, M. Li, Y. Lin, and T. Tang, "Electric vehicle's electricity consumption on a road with different slope," Physica A: Statistical Mechanics and its Applications, vol. 402, pp. 41-48, 2014.

[41] E. Ribar and J. Murín, "Road slope introduction in vehicle route modelling," in Cybernetics \& Informatics (K\&I), 2016, pp. 1-5.

[42] F. A. Kazan and R. Akkaya, "The Effect of Increases in User Weight and Road Slope on Energy Consumption in Disabled Vehicle Driven 
BALKAN JOURNAL OF ELECTRICAL \& COMPUTER ENGINEERING, Vol. 10, No. 1, January 2022

with PMSM," Balkan Journal of Electrical and Computer Engineering, vol. 9, pp. 1-7, 2021.

[43] I. Aden, H. Kahveci, and M. E. Şahin, "Single input, multiple output dcdc buck converter for electric vehicles," Turkish Journal of Electromechanics \& Energy, vol. 2, no. 2, pp. 7-13, 2017.

[44] I. A. Aden, H. Kahveci, and M. E. Şahin, "Design and Implementation of Single-Input Multiple-Output DC-DC Buck converter for Electric Vehicles," Journal of Circuits, Systems and Computers, pp. 215-228, 2021.

[45] S. Heydari, P. Fajri, M. Rasheduzzaman, and R. Sabzehgar, "Maximizing regenerative braking energy recovery of electric vehicles through dynamic low-speed cutoff point detection," IEEE Transactions on Transportation Electrification, vol. 5, no. 1, pp. 262-270, 2019.

[46] R. Akkaya and F. A. Kazan, "Design and implementation of a test setup for electric mobility scooter for the disabled," Measurement and Control, vol. 52, no. 9-10, pp. 1434-1444, 2019.

[47] ACS712 Datasheet, Allegro MicroSystems, 2017.

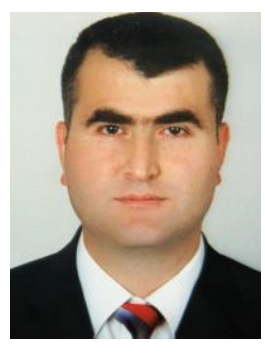

\section{BIOGRAPHIES}

FATIH ALPASLAN KAZAN was born in Amasya, Turkey. In 2002, he graduated from Electrical Education Department of Gazi University and started to work as a lecturer at Selçuk University. He completed his master's degree in Selcuk University, Institute of Science, Electrical and Electronics Engineering in 2009. He received his $\mathrm{PhD}$ degree from the Department of Electrical and Electronics Engineering of Konya Technical University in 2019. He has been working as Asst. Prof. in the Department of Aviation Electrical and Electronic of Selçuk University since 2020. His main interests are Avionic Systems, Microcontroller Applications, Measurement Systems, Circuit Design, and Motor Control.

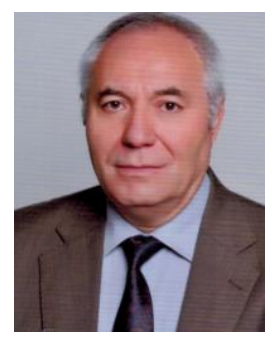

RAMAZAN AKKAYA was born in Aksaray, Turkey, in 1963. He received the B.S., M.S., and $\mathrm{PhD}$ degrees from Electrical Engineering of Yildiz Technical University, Istanbul, Turkey in 1986, 1988, and 1995, respectively. He worked as a Research Assistant between 1987 and 1995 and as an Assistant Professor between 1996 and 1998 at Yildiz Technical University Electrical Engineering Department. In 1998, he started to work at Selçuk University Electrical and Electronics Engineering Department. He became Associate Professor in 2010 and Professor in 2016 at the same university. He has been working as a Prof. Dr. in the Department of Electrical and Electronics Engineering at Konya Technical University since 2018. His main interests are Power Electronics and Applications, Control of Electric Drives, Electric Power Quality, and Renewable Energy Systems. 